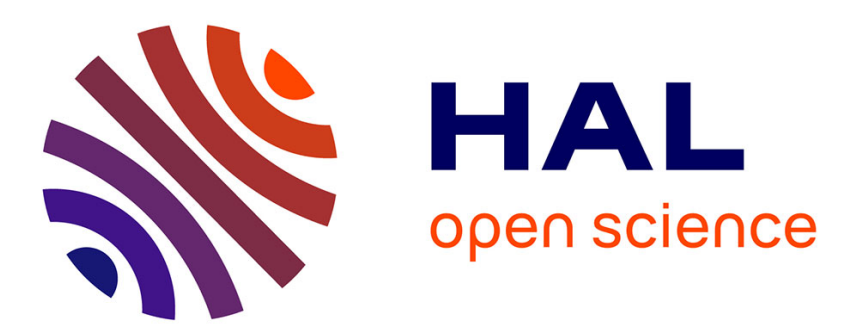

\title{
Eco-design model of a railway: A method for comparing the energy consumption of two project variants
}

Romain Bosquet, Agnès Jullien, Pierre Olivier Vandanjon, Michel Dauvergne, Flora Sanchez

\section{- To cite this version:}

Romain Bosquet, Agnès Jullien, Pierre Olivier Vandanjon, Michel Dauvergne, Flora Sanchez. Ecodesign model of a railway: A method for comparing the energy consumption of two project variants. Transportation research part D: Transport and Environment, 2014, 33, pp.111-124. 10.1016/j.trd.2014.08.003 . hal-01835743

\section{HAL Id: hal-01835743 https://hal.science/hal-01835743}

Submitted on 11 Jul 2018

HAL is a multi-disciplinary open access archive for the deposit and dissemination of scientific research documents, whether they are published or not. The documents may come from teaching and research institutions in France or abroad, or from public or private research centers.
L'archive ouverte pluridisciplinaire HAL, est destinée au dépôt et à la diffusion de documents scientifiques de niveau recherche, publiés ou non, émanant des établissements d'enseignement et de recherche français ou étrangers, des laboratoires publics ou privés. 
This is the Author's Post print version of the following article: BOSQUET, Romain, JULLIEN, Agnès, VANDANJON, Pierre Olivier, DAUVERGNE, Michel, SANCHEZ, Flora, 2014, Eco-design model of a railway: A method for comparing the energy consumption of two project variants, Transportation Research Part D: Transport and Environment, 33, ELSEVIER, pp.111-124,

DOI: https:/doi.org/10.1016/j.trd.2014.08.003

http://www.sciencedirect.com/science/article/pii/S1361920914001047

\title{
Eco-design model of a railway: A method for comparing the energy consumption of two project variants
}

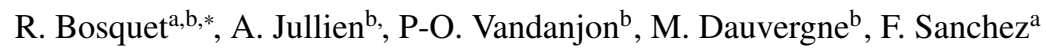 \\ ${ }^{a}$ RFF, 92 avenue de France, F-75013 Paris, France \\ ${ }^{b}$ LUNAM université, Ifsttar, ame, ease, F-44341 Bouguenais, France
}

\begin{abstract}
In accordance with the environmental concerns that national policies still address throughout the world, railways have been extensively studied to provide quantified indicators for assessing construction/operations practices.

It is essential to take energy consumption, into account since energy can be measured worldwide, in addition to constituting a global environmental load that is time-limited as regards resource availability and known as a discriminating criterion in comparing transport infrastructure. This article introduces an innovative, generic and systemic method dedicated to determining the energy consumption of a railway line during the pre-project phase by taking into account the complete life cycle of the rail infrastructure, including construction, maintenance and operations. The method developed (called «PEAM ») focuses on assessing project variants during the design stage and therefore integrates both the geometric longitudinal constraints of the line and the thicknesses/volumes over the entire itinerary as design parameters for input into the various construction scenarios. PEAM combines methodologies stemming from Life Cycle Assessment with a consumption model derived from physical modeling. The models associated with this method are then applied to study the energy consumption of a new high-speed line located in France that also has major implications for the European connections currently under investigation as well. Two project variants are compared in terms of total energy for a 50-year service life and a given characteristic rail traffic, including passenger and freight flows. Results obtained reveal a $30 \%$ difference between the two variants, which prior to applying PEAM were considered to be relatively similar.
\end{abstract}

Keywords: Energy, High-speed railway line, Operation phase, Construction phase, Montpellier-Perpignan, Variants

\section{Introduction}

At the global scale, approximately $30 \%$ of end-user energy and $62 \%$ of end-user oil is consumed by the transport sector, according to International Energy Agency (2013). Reducing the world's fuel consumption is one of the highest priorities for all countries due to energy security, greenhouse gas and economic concerns. In this context, high-speed trains (HST) offer many advantages, with an energy consumption significantly less than either road or air transport. According to Akerman (2011), high-speed trains consume roughly 4 times less energy than road transport and 9 times less than the air sector (expressed in kilowatt-hours per passenger-kilometer - $\mathrm{kWh} / \mathrm{pkm}$ ). This, among others reasons,

\footnotetext{
* corresponding author

Email addresses: romain. bosquet@gmail.com (R. Bosquet), agnes.jullien@ifsttar.fr (A. Jullien)
} 
explains why the network of high-speed lines (HSL) is still growing at a very fast pace. According to UIC (2013), some 21,365 km of high-speed lines are in operation across the world, 13,964 km are under construction and another $16,347 \mathrm{~km}$ are planned. The HSL network is expected to cover 51,677 km by 2025 .

Once it has been decided to link two cities via an HSL, the facility owner conducts an assessment of the project variants. Choosing among the various possible solutions entails a complex process that includes a range of actors (government, local authorities, local residents groups, ecological associations, etc.) and criteria (economic, environmental, technical). A clearer understanding of the tradeoffs requires suitable tools to compare the different assumptions. Since the 2000's, the environmental impacts of railways have been investigated using life cycle assessments (LCA), whereas the energy and greenhouse gas criteria are currently being evaluated.

Valuable research has previously been conducted to compare various modes of transportation from an environmental perspective (e.g. Chester and Horvath, 2009; Hoffrichter et al., 2012; Raghunathan et al., 2002; Janic, 2003). These works unfortunately did not take into account the impacts of infrastructure (e.g. see Janic 2003).

Works on HST are uncommon since conventional trains are typically studied (e.g. Chester and Horvath, 2009). Recent findings by Chester and Horvath 2009 have provided specific values for HSL and other transportation modes. These results however cannot be applied to distinguish variants since only the project length is being considered. Other works compare different train types (urban transit, conventional, high-speed), such as Garcia (2010) and Lee et al. (2011), although it is impossible to compare a given alternative using the same train technology. van Wee et al. (2003) performed breakthrough research on evaluating alternatives in the Netherlands. Different rail links with dissimilar trains have been studied. Regrettably, the method adopted to estimate the indirect energy (resulting from the infrastructure impact) is only briefly described and limited to freight infrastructure. Also, the fastest conventional trains included in the study have a maximum speed of $260 \mathrm{~km} / \mathrm{h}$, whereas project speeds of 320 or $350 \mathrm{~km} / \mathrm{h}$ are common today. Let's note that van Wee et al. (2003) did include the Maglev train, though this is not a conventional model. In conclusion, HSL offers a specific domain with its own constraints, and previously published works lack the precision required to distinguish different variants designed with the same train technology.

The method proposed in our paper has been developed to assess alternatives during the pre-project (or design) phase of a railway project. Moreover, our method takes into account both the infrastructure and its operations phase. The discrete approaches normally proposed for LCA products are adopted herein and combined with vehicle dynamic models. Both these approaches offer a well-to-wheel perspective so as to be comprehensive and take into account all phases (construction, maintenance, operations).

In the following sections, the acronym PEAM (Project Energy Assessment Method) will be used to describe our particular model. This paper continues with a full description of PEAM, which will then be applied to a real case study, i.e. a European HSL project whose life cycle phases (construction, maintenance, operations) will be studied separately as regards energy consumption. The final section will discuss the applicability of PEAM to other impacts and other projects, along with its limitations.

\section{The PEAM method for assessing project variants}

\subsection{Purpose of a variants assessment using LCA}

At the project level of a railway, the various routes (i.e. current route and variants) are examined simultaneously (Figure 1). Application of the proposed model would thus contribute to the decision-making process by focusing on the main design parameters to obtain an objective criterion for choosing a variant. Such a model could avoid controversy, such as that illustrated by Leheis (2012), and promotes better practices at the project level.

The alignment of an HSL requires mild slopes and gentle curvature. These low flexibilities of the horizontal and vertical alignment are the main causes of environmental issues as regards territorial integration. In comparison with motorways, the geometric constraints of railways require greater topographic adaptation. More specifically, a radius of plan curvature and maximum passable slope for an HSL are respectively $5 \mathrm{~km}$ and $3.5 \%$, vs. $0.6 \mathrm{~km}$ and $5 \%$ for motorways (SETRA, 2000; RFF and SNCF, 2006). It is essential to minimize the impacts of these projects on the environment. The environmental impact of major infrastructure projects is not negligible, as demonstrated by Capony et al. (2013), who compared earthworks impacts to traffic for a road project $(25 \mathrm{~km})$. The expected influential project parameters are: slope, radius of curvature, and length. An analysis of targeted objectives with an HS line model, as performed in Vandanjon et al. (2012), indicates that a continuous analysis of the HSL is indeed required in order 
to obtain a pertinent assessment. As for the structural assessment, some LCA studies focus on the railway track to generate environmental product declarations. A literature review has also been undertaken to highlight generic data at the infrastructure scale that may be reused in this context to help build our method. Botniabanan-AB (2010) expressed the functional unit as « 1 Ton.km », Lee et al. (2008) used « $1 \mathrm{~km}$ of track », and Rozycki et al. (2003) considered « 100 person. $\mathrm{km} »$ (although this was dedicated to a comparison between ballast track and concrete track). The type of railway i.e. high-speed, intercity and urban, was investigated by Chester and Horvath (2010) and Federici et al. (2009) in considering the following functional units: «Vehicle.km », «Passenger.km », and « Ton.km ». These authors focused on intermodal comparisons. Throughout all these studies therefore, it seems that the purpose of studying a given itinerary is not necessarily a typical goal of the LCA literature, although some of the individual line studies, e.g. Chang and Kendall (2011), did assess greenhouse gas emissions for high-speed railway infrastructure construction in California.

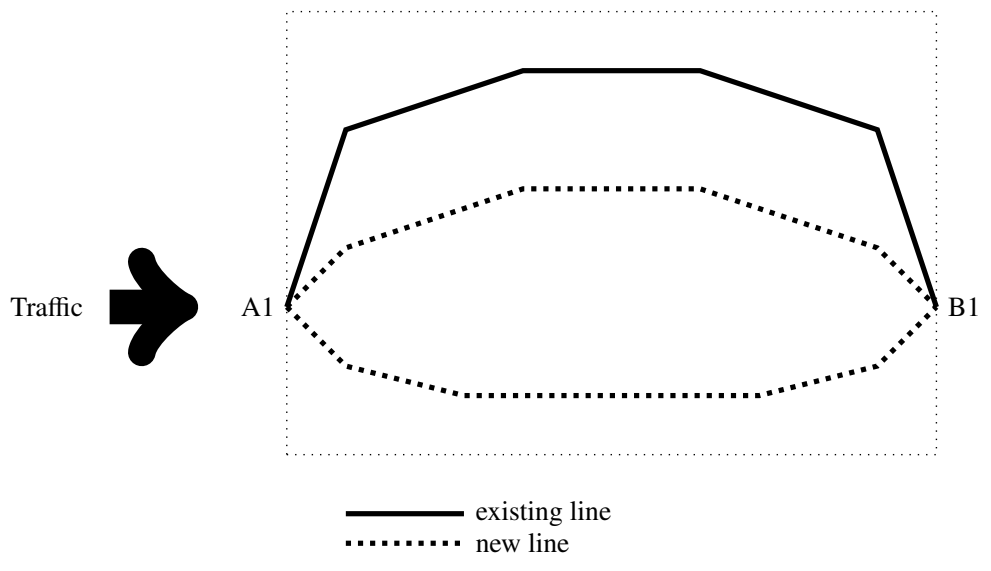

Figure 1: Theoretical example of traffic flow through a territory.

Cross-technology comparisons have been performed, as have comparisons across modes of transportation; however, the actual eco-design of a railway project has yet to be undertaken. In addition, other works have not taken into account all energy costs throughout the life of the project.

\subsection{Model set-up}

\subsubsection{Goal and scope}

The method developed herein is called PEAM; it provides an integrated framework for conducting energy assessments. PEAM includes a systemic approach based on decomposition into several functional units, including construction, maintenance, and operations of an HSL. As is typically proposed for output, each functional unit takes into account the processes of materials extraction, production, transportation (truck, train, boat), and on-site works using non-road equipment, with verification of material consumption. The main goal of this method is to estimate the energy consumed over the entire life cycle in adapting the LCA framework.

The models introduced to evaluate project energy consumption as regards construction and maintenance use data associated with a long list of materials and processes needed to build the linear portions of the route, along with the bridges, tunnels and viaducts. Rehabilitation of the road network after insertion of an HSL is also considered. The generic data were collected from the literature, whereas the specific project data were obtained from HSL bids, namely French projects for the present study. Such data collection methods and principles have also been discussed by Chang and Kendall (2011) and Rozycki et al. (2003).

Our method is thus based on a continuous approach along the HSL alignment by taking into account these functional units (FU) and aggregating them to describe the entire HSL. Depending on the line design, some of these elementary FU, which turn out to be geometry-dependent, vary and therefore allow proceeding with a generic project approach. As for the other elementary FU, they can also be considered as generic and hence provide an energy consumption ratio per $\mathrm{km}$ of line. PEAM also assumes, as shown in Figure 1, that the traffic is being handled by 
several existing railway lines within a given territory. The method thus assesses different pre-project possibilities: the implementation of either one single new line or several lines.

PEAM proposes a combined approach for pre-project variant assessment that relies on a system dedicated to a flow of trains crossing a territory on an infrastructure with given longitudinal and transverse profiles. The whole environmental system can then provide mobility services within a territory for given number of years. As regards territorial aspects, the PEAM method includes localization concepts not usually considered within the LCA framework, which nonetheless offer a scalar assessment derived from the LCA in combination with vehicle dynamic modeling methods. This set-up takes into account the longitudinal track profile at the project scale and therefore the final HSL geometry sought by the project owner. The entire method, as presented herein, has been generated from previous work dedicated to project data collection:

i) Vandanjon et al. (2012) concentrated on the purpose of a single HSL assessment using LCA at the project stage. Their work has been adapted here to make use of the available data, albeit at the pre-project stage, which has lead to introducing the longitudinal profile of variants as considered through variant lengths, slopes and curves;

ii) Bosquet et al. (2013) proposed a complete train model, as validated at the full-scale by tests using high-speed trains. The applicability of their method will be investigated in this paper.

\subsubsection{Itinerary discretization and specific functional units}

PEAM is intended to offer a unified LCA-based method for both construction/maintenance assessment and operations modeling, whereas these two topics are usually investigated separately in the literature. Any itinerary is naturally tied to a given high-speed line project, since it takes into account local territorial constraints in defining the numbers of bridges, tunnels, viaducts and earthmoving equipment (due to the route alignment) as well as the distances between the points to be connected in crossing the given territory (see Fig. 1, points A1 and B1). Each project is thus different and a case-by-case assessment needs to be performed. PEAM however defines a global functional unit to assess any itinerary of interest, as displayed in Figure 2, which has been broken down into 3 subfigures: Figs. 2a, 2b and 2c. Figure 2a shows the complete functions associated with the full HSL. The total project length is recorded as $l_{t o t}$. This total function, associated with a total functional unit, is then subdivided into 2 subunits: i) Fig. $2 \mathrm{~b}$ pertains to the use phase; ii) Fig. 2c pertains to the construction and maintenance of linear infrastructure sections and works, as well as to the consequences of line integration into the studied territory (new construction). The infrastructure phase is broken down into 6 elementary functional units (efu 1 through 6), as described below.

Hence, some elementary functional units can be considered as either generic or specific, as will be discussed below:

- efu 1: This efu assesses the total earthworks involved in the resulting cut and fill on the project area using local data on the new project. For the works assessments component, consumption ratios are used. Capony et al. (2013) applied such ratios to cut volumes, fill volumes, on-site transport distances, earthmoving distances (cuts to fills) and materials supplied from outside the HSL works area. This efu uses specific data at the pre-project step;

- efu 2: This efu assesses construction of the civil engineering structures including bridges, viaducts and tunnels. The tunnel length $\left(l_{t}\right.$, Fig. $\left.2 \mathrm{c}\right)$, viaduct length $\left(l_{v}\right.$, Fig. $\left.2 \mathrm{c}\right)$ and bridge volume $\left(v_{b}\right.$, Fig. $\left.2 \mathrm{c}\right)$ are calculated from this new project layout. Beginning with the unitary result expressed per kilometer and cubic meter for each kind of structure, the energy can then be calculated. This efu is project-specific;

- efu 3: This efu assesses the total number of $\mathrm{km}$ of sewer drain construction. $l_{\text {tot }}$ (Fig. 2c) is used for this purpose. This efu can be considered as generic for French HSL;

- efu 4: This efu assesses total road rehabilitation and construction based on a per-kilometer ratio along the total line length $\left(l_{\text {tot }}\right.$, Fig. $\left.2 \mathrm{c}\right)$. This efu provides a generic assessment of road connections within France; 
(a)
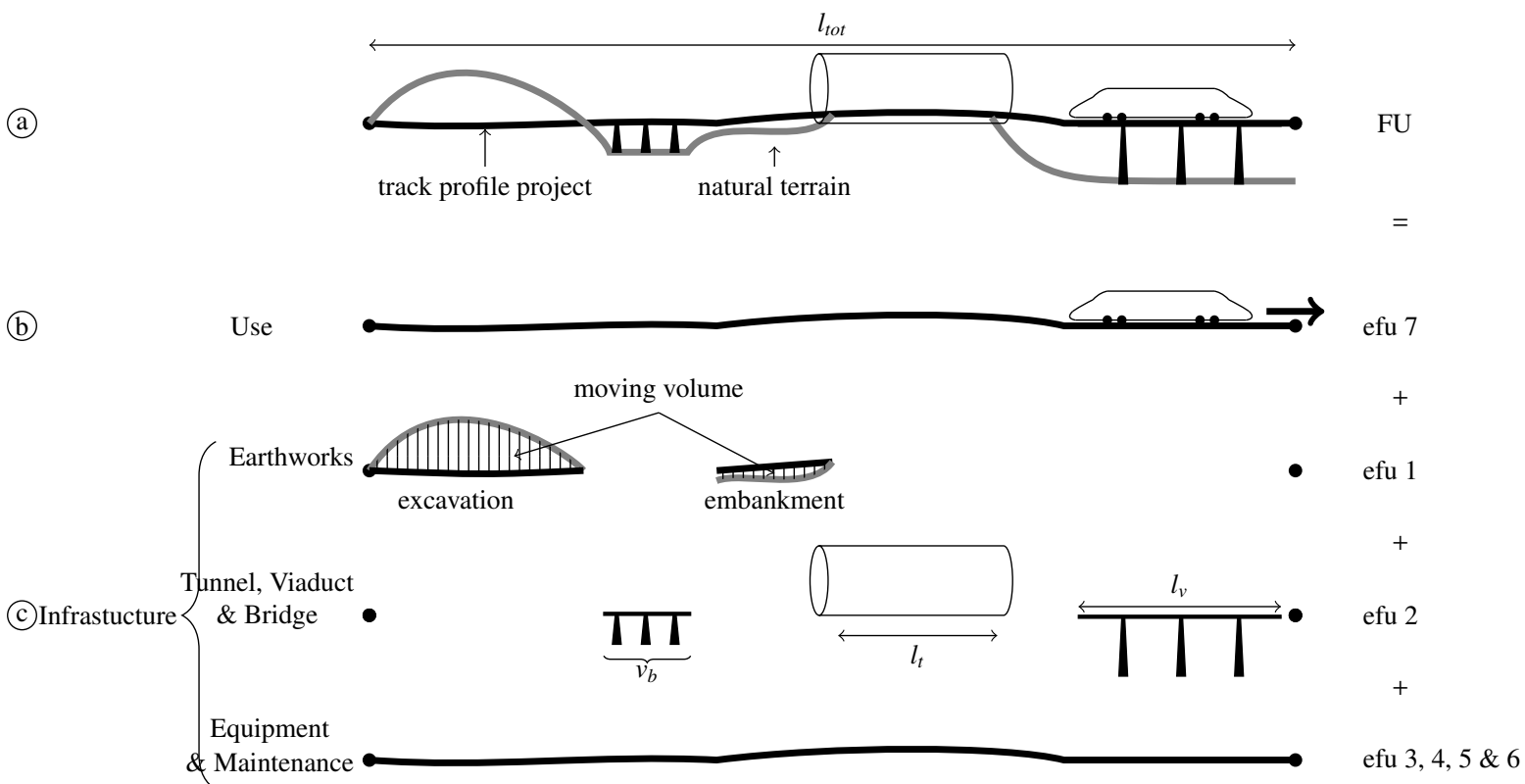

Figure 2: Line discretization for itinerary assessment and elementary functional units.

- efu 5: This efu assesses the number of $\mathrm{km}$ of railway foundation construction and maintenance of railroad lines, ballast and sleepers (along the total length, $l_{t o t}$ ). This efu is generic for railway projects in France;

- efu 6: This efu assesses the number of $\mathrm{km}$ of railway equipment construction (signaling, cables, catenary, etc.) along the total length, $l_{\text {tot }}$. This efu is also generic for railway projects in France;

- efu 7: This efu assesses the operations phase (train traffic). It is specific to a given project and typically depends on the territory being crossed; hence, a model is presented to assess the line along its longitudinal profile..

\subsubsection{Modeling steps}

Since no studies in the literature that perform LCA actually deal with itineraries given that they focus on passenger mobility, the present study starts with a dedicated data collection effort specific to railway itinerary, as defined by the owner in calls for tender and contractor selection procedures. All documents provided by the French project owner (RFF) and made available for two high-speed lines already in service were then reviewed in order to analyze existing HSL projects.

To develop the first six efu, several case studies of high-speed railway lines were taken into account for data collection purposes. $400 \mathrm{~km}$ of existing lines were investigated as a basis for our assessment. From these projects, a set of generic life cycle inventory (LCI) data was extracted to assess the functional unit of a new project. The links between geometry and environmental systems considered are shown on Figure 3. This step led to considering elementary data at the efu i level, as expressed per kilometer of HSL.

Moreover, the power consumption of train motion (efu 7) is estimated in several steps, as indicated on Figure 4. The first step simulates the mechanical power provided by motors. Train characteristics, the track profile, travel time and initial speed constitute the required initial input. The second step outputs the estimated power consumed at the pantograph. Traction system losses need to be modeled, and the energy exchanged by the train is determined by 


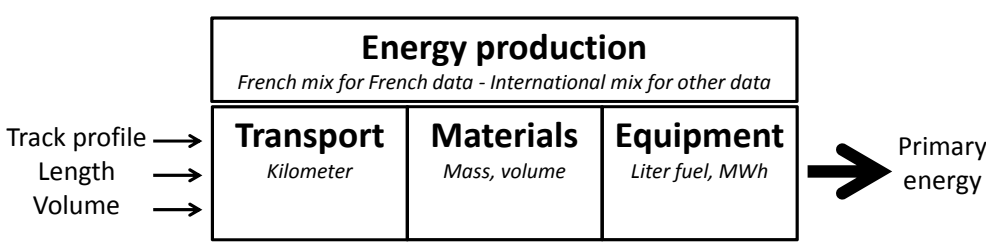

Figure 3: System for performing construction/maintenance assessments.

mathematically integrating the power. Lastly, line losses are taken into account and the primary energy required to produce electricity is estimated.

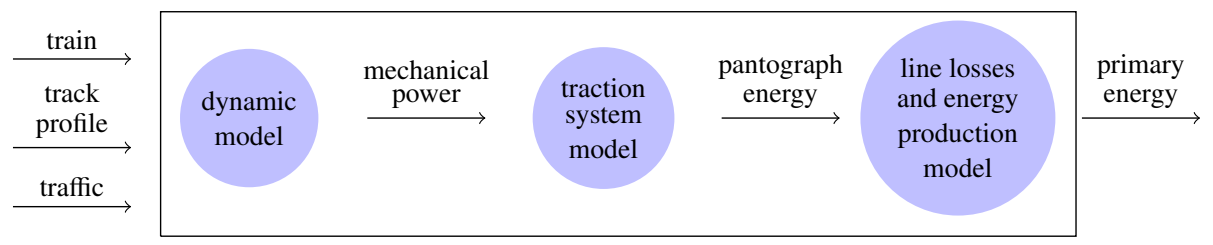

Figure 4: Steps during the operations phase for model development.

\subsubsection{Energy consumption modeling during the construction and maintenance phases}

Each elementary functional unit (efu) is described by a system (see Fig. 3) composed of processes, input material flows and an output primary energy flow. The transport component is always a parameterized data element. In order to assess the environmental impact of an HSL itinerary, the functional unit must describe the technical features of railway track and traffic patterns along the itinerary as input into the track design.

The models applied to assess energy consumption for construction and maintenance use unit consumption data associated with an extensive list of materials tied to the processes required to build the linear portions of the line, along with the bridges, tunnels and viaducts. Such data, when in generic form, were collected from the literature and have been detailed in the present paper, whereas the specific data were obtained from HSL project bids, namely from French projects cited in the present study. This method and data collection principles were also employed by Chang and Kendall (2011), who assessed greenhouse gas emissions for high-speed railway infrastructure construction in California.

All of the documents available for two French high-speed lines (LGV Est and LGV Rhin-Rhône) in eastern France were then reviewed in order to analyze existing projects. This protocol provided a description of material supply along a given project alignment, plus the generic data for the elementary functional units efu 2 through efu 6 . It can be stated that efu 1 and efu 7 are specific to the route relative to the HSL case study and territory being crossed; moreover, these two units are based on the actual longitudinal profile. efu 2 to 6 are, on the other hand, correlated with the project length while remaining constant along the given line. Tables 1 and 2 provide the details of material consumption for the studied project, as well as data sources for the energy consumption and energy mix.

The models for assessing energy consumption during construction and maintenance also use consumption data in association with an extensive list of materials and processes required to build the linear portions of the line, along with the bridges, tunnels and viaducts. Such data in generic form were collected from the literature and detailed herein, and once again the specific data were all obtained from HSL project bids, i.e. the cited French projects. As mentioned above, this method and data collection principles were displayed by Chang and Kendall (2011) during their greenhouse gas emissions assessment for high-speed railway infrastructure projects in California.

Table 1 lists the descriptions of efu 1 and efu 2 in presenting the raw data tied to material consumption and transport. Table 2 then details these same data but for efu 3 through efu 6. 
Table 1: Description of efu 1 and efu 2.

\begin{tabular}{|c|c|c|c|c|c|}
\hline \multicolumn{2}{|r|}{$\mathrm{Efu}_{\mathrm{i}}$} & Main processes & $\begin{array}{l}\text { Amount to } \\
\text { build } \mathrm{Efu}_{\mathrm{i}}\end{array}$ & $\begin{array}{l}\text { Distance } \\
\text { supply } \\
(\mathrm{km})\end{array}$ & Source \\
\hline \multirow{5}{*}{ 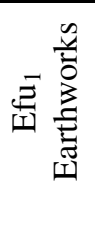 } & & Cuts $\left(1 / \mathrm{m}^{3}\right)$ & 0.20 & \multirow{5}{*}{$\begin{array}{l}\text { Depending } \\
\text { on the } \\
\text { case } \\
\text { study }\end{array}$} & \multirow{5}{*}{ Jullien et al.2012 } \\
\hline & & Fills $\left(1 / \mathrm{m}^{3}\right)$ & 0.25 to 0.30 & & \\
\hline & & Rock cuttings $\left(1 / \mathrm{m}^{3}\right)$ & 0.35 & & \\
\hline & & $\begin{array}{l}\text { Crushing, screening } \\
\left(1 / \mathrm{m}^{3}\right)\end{array}$ & 0.90 to 1.30 & & \\
\hline & & Transport $\left(\mathrm{l} / \mathrm{m}^{3} / \mathrm{km}\right)$ & 0.40 & & \\
\hline \multirow{24}{*}{ 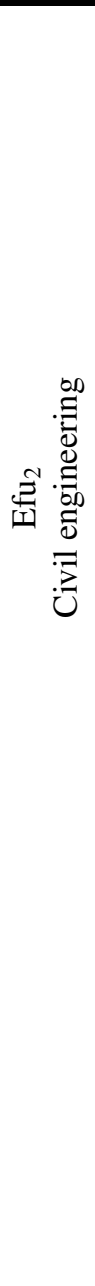 } & \multirow{3}{*}{ Bridges } & Reinforcing steel $\left(\mathrm{t} / \mathrm{m}^{3}\right)$ & 0.07 & 100 & \multirow{3}{*}{$\begin{array}{l}\text { Process "Ecoinvent" } \\
\text { adapted }\end{array}$} \\
\hline & & Concrete $\left(\mathrm{m}^{3} / \mathrm{m}^{3}\right)$ & 1.04 & 29 & \\
\hline & & Equipement fuel $\left(1 / \mathrm{m}^{3}\right)$ & 1.97 & & \\
\hline & \multirow{5}{*}{ Viaducts } & $\begin{array}{l}\text { Reinforcing steel and } \\
\text { structural steel }(\mathrm{t} / \mathrm{km})\end{array}$ & 6800 & 100 & \multirow{5}{*}{$\begin{array}{c}\text { Process "Ecoinvent" } \\
\text { adapted }\end{array}$} \\
\hline & & Concrete $\left(\mathrm{m}^{3} / \mathrm{km}\right)$ & 23500 & 29 & \\
\hline & & Aggregates $(\mathrm{t} / \mathrm{km})$ & 32000 & & \\
\hline & & $\begin{array}{l}\text { Hydraulically bound } \\
\text { materials }(\mathrm{t} / \mathrm{km})\end{array}$ & 4200 & & \\
\hline & & Equipement fuel $\left(1 / \mathrm{m}^{3}\right)$ & 290000 & & \\
\hline & \multirow{4}{*}{$\begin{array}{l}\text { Two-tube tunnel } \\
\text { dug with TBM }\end{array}$} & Reinforcing steel (t/km) & 2100 & 100 & $\begin{array}{c}\text { Process "Ecoinvent" } \\
\text { adapted }\end{array}$ \\
\hline & & Concrete $\left(\mathrm{m}^{3} / \mathrm{km}\right)$ & 47500 & 50 & Ecorce 2.0 \\
\hline & & TBM (MWh/km) & 7850 & & AFNOR FDP 01-015 \\
\hline & & Equipement fuel (1/km) & 20000 & & Ecorce 2.0 \\
\hline & \multirow{3}{*}{$\begin{array}{l}\text { Two-tube tunnel } \\
\text { dug } \\
\text { conventionally }\end{array}$} & Reinforcing steel (t/km) & 4300 & 100 & $\begin{array}{c}\text { Process "Ecoinvent" } \\
\text { adapted }\end{array}$ \\
\hline & & Concrete $\left(\mathrm{m}^{3} / \mathrm{km}\right)$ & 70000 & 50 & \multirow{2}{*}{ Ecorce 2.0} \\
\hline & & Equipement fuel (1/km) & 500000 & & \\
\hline & \multirow{3}{*}{$\begin{array}{l}\text { Trench covered } \\
\text { with two tubes }\end{array}$} & Reinforcing steel $(\mathrm{t} / \mathrm{km})$ & 8800 & 100 & $\begin{array}{c}\text { Process "Ecoinvent" } \\
\text { adapted }\end{array}$ \\
\hline & & Concrete $\left(\mathrm{m}^{3} / \mathrm{km}\right)$ & 88000 & 50 & \multirow{2}{*}{ Ecorce 2.0} \\
\hline & & Equipement fuel (1/km) & 450000 & & \\
\hline & \multirow{3}{*}{$\begin{array}{c}\text { Monotube } \\
\text { tunnel dug } \\
\text { conventionally }\end{array}$} & Reinforcing steel $(\mathrm{t} / \mathrm{km})$ & 3600 & 100 & $\begin{array}{c}\text { Process "Ecoinvent" } \\
\text { adapted }\end{array}$ \\
\hline & & Concrete $\left(\mathrm{m}^{3} / \mathrm{km}\right)$ & 58000 & 50 & \multirow{2}{*}{ Ecorce 2.0} \\
\hline & & Equipement fuel (1/km) & 260000 & & \\
\hline & \multirow{3}{*}{$\begin{array}{l}\text { Covered trench } \\
\text { monotube }\end{array}$} & Reinforcing steel (t/km) & 5800 & 100 & $\begin{array}{c}\text { Process "Ecoinvent" } \\
\text { adapted }\end{array}$ \\
\hline & & Concrete $\left(\mathrm{m}^{3} / \mathrm{km}\right)$ & 58000 & 50 & \multirow{2}{*}{ Ecorce 2.0} \\
\hline & & Equipement fuel (1/km) & 420000 & & \\
\hline
\end{tabular}


Table 2: Description of efu 3 through 6.

\begin{tabular}{|c|c|c|c|c|}
\hline $\mathrm{Efu}_{\mathrm{i}}$ & Main processes & $\begin{array}{l}\text { Amount to } \\
\text { build } \mathrm{Efu}_{\mathrm{i}}\end{array}$ & $\begin{array}{c}\text { Distance } \\
\text { supply } \\
(\mathrm{km})\end{array}$ & Source \\
\hline \multirow{6}{*}{ 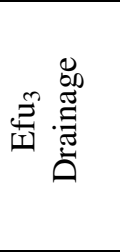 } & $\mathrm{PVC}(\mathrm{t} / \mathrm{km})$ & 69 & 100 & \multirow[t]{2}{*}{ Process "ecoinvent" adapted } \\
\hline & Reinforcing steel (t/km) & 2.4 & & \\
\hline & Aggregates $^{1}(\mathrm{t} / \mathrm{km})$ & 245 & 30 & \multirow{4}{*}{ Ecorce 2.0} \\
\hline & Cement $(\mathrm{t} / \mathrm{km})$ & 47 & 300 & \\
\hline & Concrete $(\mathrm{t} / \mathrm{km})$ & 316 & 100 & \\
\hline & Equipment fuel (1/km) & 2400 & & \\
\hline \multirow{10}{*}{ 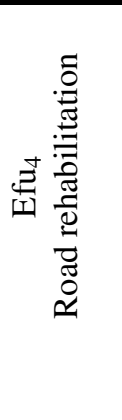 } & $\mathrm{PVC}(\mathrm{t} / \mathrm{km})$ & 0.14 & 200 & \multirow{2}{*}{$\begin{array}{l}\text { Process "ecoinvent" } \\
\text { adapted }\end{array}$} \\
\hline & Reinforcing steel (t/km) & 16 & & \\
\hline & Aggregates $^{2}(\mathrm{t} / \mathrm{km})$ & 5900 & 30 & \multirow{8}{*}{ Ecorce 2.0} \\
\hline & Cement $(\mathrm{t} / \mathrm{km})$ & 88 & 300 & \\
\hline & Concrete $(\mathrm{t} / \mathrm{km})$ & 41 & 30 & \\
\hline & Bitumen (t/km) & 47 & 270 & \\
\hline & Hydraulically bound & & & \\
\hline & materials $(\mathrm{t} / \mathrm{km})$ & 3100 & 100 & \\
\hline & Asphalt concrete $(\mathrm{t} / \mathrm{km})$ & 900 & 30 & \\
\hline & Equipment fuel (1/km) & 1500 & & \\
\hline \multirow{7}{*}{ 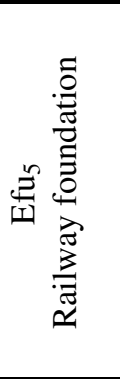 } & $\begin{array}{l}\text { Reinforcing steel } \\
\text { (railway sleeper) }(\mathrm{t} / \mathrm{km})\end{array}$ & 35 & 500 & \multirow{7}{*}{$\begin{array}{c}\text { Process "ecoinvent" } \\
\text { adapted }\end{array}$} \\
\hline & Steel rail $(\mathrm{t} / \mathrm{km})$ & 240 & 500 & \\
\hline & $\begin{array}{l}\text { Cement (railway } \\
\text { sleeper) }(\mathrm{t} / \mathrm{km})\end{array}$ & 130 & 150 & \\
\hline & Concrete (railway & & & \\
\hline & sleeper $)(\mathrm{t} / \mathrm{km})$ & 1040 & 30 & \\
\hline & Ballast $(\mathrm{t} / \mathrm{km})$ & 8300 & 200 & \\
\hline & Equipment fuel (l/km) & 55000 & & \\
\hline \multirow{13}{*}{ 总 } & Steel $(\mathrm{t} / \mathrm{km})$ & 42 & \multirow{13}{*}{$\begin{array}{c}\text { Average } \\
130\end{array}$} & Ecorce 2.0 \\
\hline & Aluminium $(\mathrm{t} / \mathrm{km})$ & 0.11 & & \multirow{5}{*}{$\begin{array}{l}\text { Process "ecoinvent" } \\
\text { adapted }\end{array}$} \\
\hline & Bronze $(\mathrm{t} / \mathrm{km})$ & 0.01 & & \\
\hline & Copper $(\mathrm{t} / \mathrm{km})$ & 5.2 & & \\
\hline & Cast iron $(\mathrm{t} / \mathrm{km})$ & 4.5 & & \\
\hline & Stainless steel (t/km) & 0.003 & & \\
\hline & Concrete $(\mathrm{t} / \mathrm{km})$ & 179 & & Ecorce 2.0 \\
\hline & HDPE (t/km) & 4.5 & & \multirow{2}{*}{$\begin{array}{c}\text { Process "ecoinvent" } \\
\text { adapted }\end{array}$} \\
\hline & $\mathrm{PVC}(\mathrm{t} / \mathrm{km})$ & 1 & & \\
\hline & Aggregates (t/km) & 290 & & \multirow{2}{*}{ Ecorce 2.0} \\
\hline & Cement $(\mathrm{t} / \mathrm{km})$ & 1.7 & & \\
\hline & Optical fiber $(\mathrm{t} / \mathrm{km})$ & 0.5 & & Process "ecoinvent" adapted \\
\hline & Equipment fuel (l/km) & 2400 & & Ecorce 2.0 \\
\hline
\end{tabular}

${ }^{1}$ including concrete aggregates

2 including concrete aggregates, hydraulically bound material aggregates, and asphalt concrete aggregates 


\subsubsection{Modeling of energy consumption during the operations phase}

In this section, the efu 7 evaluation will be completely described with respect to this paper's objective, namely providing a fine-tuned comparison of HSL variants in order to assess the project's energy consumption throughout its entire life cycle.

Dynamic model. This model development process began with a review of train consumption models. To estimate the electricity consumption of high-speed trains, the forces acting on the train were first investigated in the literature. Lukaszewicz (2007) and Rochard and Schmid (2000) offered interesting general formulations of operational performance as a function of train characteristics like mass, number of bogies, inter-vehicle gap and number of pantographs. To estimate energy consumption, the train is considered as a point with mass M (Rochard and Schmid, 2000). Newton's second law is then applied at this point, as expressed in Equation 1. The total force conveyed to the drive wheels by the electric motor is computed in Equation 4.

As discussed in the introduction, the results of these publications are not directly applicable to this study because they lack the precision needed to distinguish two variants. For this reason, we relied on the methodology described in these papers to build a suitable model for our intended purpose.

The forces balance is obtained from Newton's second law applied to the train, i.e.:

$$
k \cdot \mathrm{M} \cdot \gamma=\mathrm{F}-\mathrm{M} \cdot \mathrm{g} \cdot \sin (\alpha)-\mathrm{F}_{\mathrm{r}}-\mathrm{F}_{\mathrm{c}}:
$$

where on the left-hand side of Equation (1):

- $\mathrm{M}$ is the train mass;

- $k$ is the coefficient of inertia of rotating masses (rather than modeling the entire mechanical system, it has been preferred to multiply the mass by a constant);

- $\gamma$ is the longitudinal acceleration;

For the right-hand side of Equation (1):

- F denotes the total force conveyed to the drive wheels by the electric motor;

- $\mathrm{g}$ is the gravity acceleration and $\alpha$ is the local gradient of the line;

- $\mathrm{F}_{\mathrm{r}}$ is the resistance force;

- $\mathrm{F}_{\mathrm{c}}$ is the resistance force in curvature.

$F_{r}$ is composed of the following physical effects: i) rolling resistance, which is related to the contact wheel rail. As an initial approximation, it is considered to be constant (due to the sticking effect, this value is not the same when the train is stopped or set into motion); ii) mechanical resistance, which consists of a viscous friction $F c$, mainly dependent on velocity, and dry friction $F s$, considered as constant (unless the train is starting up, like for the rolling resistance); and iii) aerodynamic resistance, related to drag coefficient $C x$ and weather conditions (e.g. wind, rain). This composite resistance depends primarily on the velocity squared. By taking the previous physical interpretation into account, this resistance force $\left(\mathrm{F}_{\mathrm{r}}\right)$ is approximated by a second-order polynomial (Rochard and Schmid, 2000):

$$
\mathrm{F}_{\mathrm{r}}=A+B \cdot V+C \cdot V^{2}
$$

Where:

- $V$ is the train velocity;

- $A, B, C$ are coefficients dependent on the rolling stock.

$\mathrm{F}_{\mathrm{c}}$ (the resistance force in curvature) is modeled by using the classical formula given in both Fayet (2008) and Rochard and Schmid (2000):

$$
\mathrm{F}_{\mathrm{c}}=\mathrm{M} \cdot 9.81 \cdot \sin \left(\frac{0.8}{R_{c}}\right)
$$


- $R_{c}$ is the curvature radius in a horizontal plane.

To model driving, the driving rules need to be described. Two speed limits are introduced. The first limit is the set point speed. If the train speed lies below this set point (i.e. case 1), then F is positive. The second limit is the maximum speed. If train speed lies between the set point and the maximum limit (case 2), then $\mathrm{F}$ is zero. When the speed exceeds the maximum (case 3), $\mathrm{F}$ is negative. These three cases are summarized in Figure 5 with an example of set point and maximum speed limits.

case 3, braking, $F<0$

limit speed

case 2, coasting, $F=0$

set point speed

case 1 , traction, $F>0$

Figure 5: Driving model hypotheses.

Driver behavior in cases 1 and 3 is modeled by means of a proportional integral corrector. The two coefficients are chosen so that force $F$ is maximized if the speed deviation exceeds $10 \mathrm{~m} / \mathrm{s}$. The set point speed is chosen to satisfy the travel time constraint while the maximum speed limit is set by safety restrictions.

A classical numerical method (Adams method) is introduced to solve the differential equation. The initial conditions (position and speed) are selected on the basis of the study area. The integration of these ordinary differential equations yields the position, speed and force $\mathrm{F}$ provided by the motors along the section length. To estimate the mechanical power generated by the motor, $\mathrm{F}$ is multiplied by the speed:

$$
P_{\text {provided }}=F \cdot V
$$

Figure 6 summarizes the steps required to obtain mechanical power.

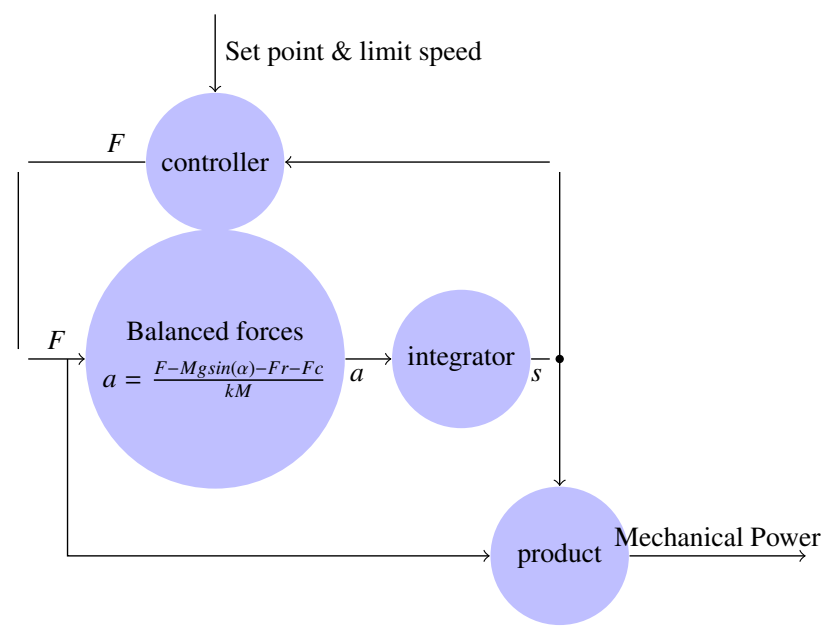

Figure 6: Dynamic model steps. 
Energy pantograph simulation. As demonstrated by Jeunesse and Rollin (2004), Lindgreen and Sorenson (2005) and Boullanger (2008), the electricity consumption can be deduced by introducing a ratio $\eta$ that illustrates the efficiency of the traction system and its auxiliary equipment:

$$
\begin{aligned}
& \text { if } P_{\text {provided }}>0 \text { then } P=P_{\text {provided }} \cdot(1 / \eta)+\beta \\
& \text { if } P_{\text {provided }}<0 \text { then } P=P_{\text {provided }} \cdot \eta+\beta
\end{aligned}
$$

where :

- $\beta$ is the auxiliary. It represents the power consumed to enhance comfort (heating, lighting, etc.) as well as for equipment, such as ventilation and cooling of propulsion equipment and compressed air supply for brakes;

- $\eta$ is the traction system efficiency. As an initial approximation, this efficiency is considered constant.

The consumed power is then integrated in order to obtain energy consumption.

$$
E=\int_{\text {time }} P_{\text {consumed }}
$$

Equation 5 implies that negative energy (i.e. when the train uses its regenerative brakes) is directly subtracted from the consumed energy, which is a key point in the energy balance of a high-speed train in comparison with other modes of transport like cars and airplanes.

Primary energy expended. The final model step is to estimate the primary energy consumed to supply the train. Losses stem from two sources; i) the system for transporting electric power from the catenary to the power station; and ii) electric energy production, which generally converts thermal energy (nuclear, gas, etc.), hydro, solar or mechanical power into electric energy. The first category of losses depends on the transport system (voltage, frequency, etc.), whereas the second depends on each country's energy supply mix. As is the case for construction and maintenance, if the energy is consumed in France, the French energy mix will be considered. Other scenarios can easily be investigated.

\section{Results}

\subsection{Presentation of case study}

The European high-speed network has grown considerably in recent years. As observed in Figure 7, this network still has some missing connections, especially between Montpellier and Perpignan (see the black circle in the figure), which has been chosen as our project case study. To a greater extent further south, the section of line between Perpignan and Figueras has been in service since 2013. Over the northern part of the line, RFF (railroad owner) is currently building a section between Nimes and Montpellier. With the completed Montpellier-Perpignan line integrated into the actual network, trains will therefore be continuously circulating at high speed between Paris and Madrid.

The proposed new high-speed line should meet a certain number of demands resulting from a fast-growing transport sector, namely: i) capacity shortage problems now as important an issue as speed; ii) the increased volumes of railway freight as an alternative to road transport; iii) expanded regional express train service in an area with high population density along the coast and with high traffic levels. Lastly, the new Montpellier-Perpignan line can be qualified, according to the above considerations, as a major rail project to cross Europe and will handle 124 freight trains a day (124 FT/d) and 42 passenger trains a day (42 PT/d). 


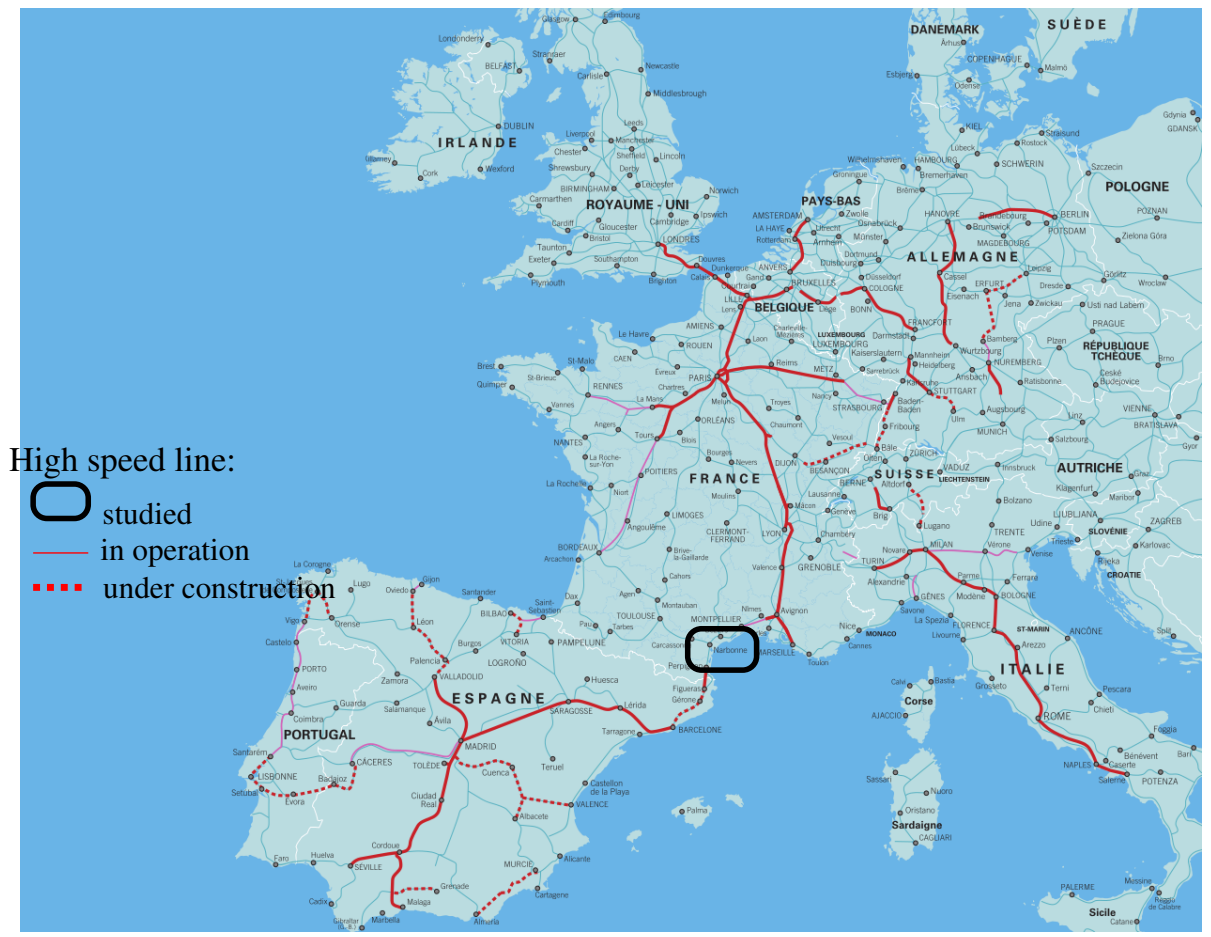

Figure 7: European high-speed line (speed $>220 \mathrm{~km} / \mathrm{h}$ ) in 2009, RFF (2009), with the situation of the Montpellier-Perpignan project.

\subsection{Scenarios considered}

Of the $155-\mathrm{km}$ long project line, the studied line covers about $25 \mathrm{~km}$ (this length will vary to some extent depending on the variant). Over this section, two scenarios are proposed: a new high-speed line dedicated to passenger trains (NPL), and a new mixed line for passenger and freight trains (NML). In both cases, the existing line (a conventional line - CL) will be kept in service. PEAM is therefore applied to compare both variants. Figure 8 shows the traffic distribution between the new line (connecting points A1 and B1) and the existing line (point A2 to point B2) for the studied scenarios. For the NPL, the traffic equals $42 \mathrm{PT} / \mathrm{d}$ on the new line and $124 \mathrm{FT} / \mathrm{d}$ on the conventional line. As for the NML, the traffic is: $42 \mathrm{PT} / \mathrm{d}$ plus $43 \mathrm{FT} / \mathrm{d}$ on the new line, and $81 \mathrm{FT} / \mathrm{d}$ on the conventional line.

The maximum overall capacity of the two projects differs. More NPL trains can cross the area because the NML is able to combine fast and slow trains, with traffic forecasts however far from reaching saturation.

The longitudinal profiles corresponding to the lines of these two scenarios differ as well. The maximum gradient of the NPL is $35 \mathrm{~mm} / \mathrm{m}$ while this figure is $12.5 \mathrm{~mm} / \mathrm{m}$ for NML as a result of the more stringent restrictions placed on freight trains. Moreover, the relevant lengths are different. Between the same pair of departure and arrival points (A1 and B1 in Fig. 8), the length equals $22.3 \mathrm{~km}$ for NPL and $25.3 \mathrm{~km}$ for NML. The infrastructure components, according to Figure 2 (line, bridges, etc.), are also differently distributed for these two scenarios. The total length of tunnels, viaducts and bridges varies, and this variation influences the overall assessment of the functional unit. As a final consideration, the FU for both variants is: 42 PT plus 124 FT per day during a 50-year period within a given area spanning $25 \mathrm{~km}$ x $5 \mathrm{~km}$. 


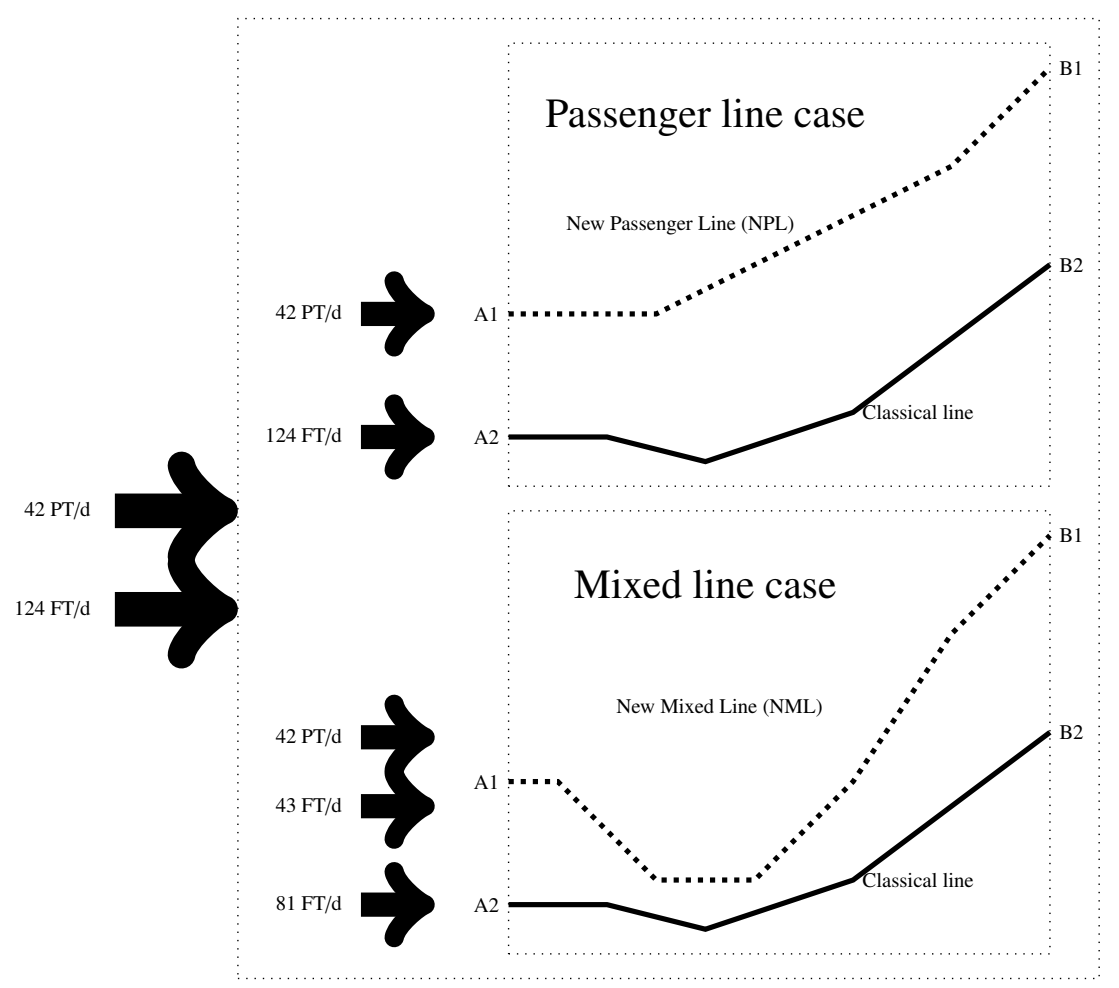

Figure 8: Traffic as a function of variant scenario.

\subsection{Construction phase results}

The energy consumption evaluation for the efu and variants is obtained from the data as follows. Data on efu 1 and efu 2 have been compiled in Table 3 as regards volumes moved or worked. For efu 1, i.e. earthworks data, the excess excavated materials are moved in assuming a 15-km transport distance. As for efu 2, several types of civil engineering structures are taken into account (bridges, viaducts, tunnels, trenches); moreover, cement CEM I is considered for each structure.

\begin{tabular}{lll}
\multicolumn{2}{c}{ Table 3: Refined data for efu 1 and efu 2 in relation to the variants. } \\
\hline TOTAL & $\begin{array}{l}\text { Mixed line NML } \\
\text { Length: 25.273 km }\end{array}$ & $\begin{array}{l}\text { Passenger line NPL } \\
\text { Length : 22.287 km }\end{array}$ \\
\hline Efu 1 / Cuts & $1,700,000 \mathrm{~m}^{3}$ & $10,000,000 \mathrm{~m}^{3}$ \\
Efu 2 / Bridges & $49,901 \mathrm{~m}^{3}$ & $80,028 \mathrm{~m}^{3}$ \\
Efu 2 / Viaducts & $1.592 \mathrm{~km}$ & $1.061 \mathrm{~km}$ \\
Efu 2 / Tunnels (tunneling) & $3.2+2.75 \mathrm{~km}$ & 0 \\
Efu 2 / Tunnel (conven- & $1.5 \mathrm{~km}$ & $0.3 \mathrm{~km}$ \\
tional) & & \\
Efu 2 / Trenches (covered) & $0.36 \mathrm{~km}$ & $0.6 \mathrm{~km}$ \\
\hline
\end{tabular}

According to the total energy consumption result, the NML (Fig. 9) costs more energy per FU: 3,300 Tera Joules (TJ) for NML vs. 1,800 TJ for NPL. As observed in Figure 9, which exhibits the ratio of each efu to the whole construction task, this finding is mainly due to the tunnels required for the mixed line (2,054 TJ for NML vs. 207 TJ). It is also found that the earthmoving phase accounts for $36 \%$ with NPL. The characteristics of spoils and banks are obviously critical for this scenario. 

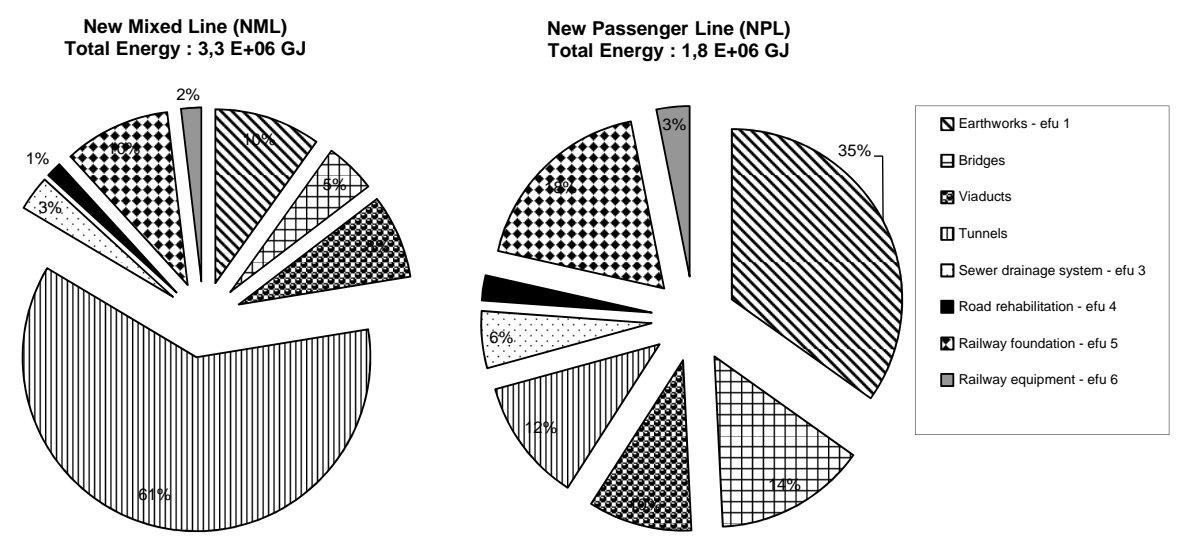

Figure 9: Construction energy requirements (NML vs. NPL).

\subsection{Maintenance phase results}

Maintenance works only concern efu 5 as regards the FU chosen for the present study.

Maintenance operations under both scenarios are assumed to be equivalent per $\mathrm{km}$ in the present study since no discriminating data are available to provide any means of distinction. The difference in traffic between the two lines is not significantly sufficient to highlight any change in maintenance principle. Hence, the hypotheses forwarded are that the rail is renewed after 25 and 50 years, the ballast is renewed after 30 and 50 years, and sleepers after 50 years. Similar process, material and transport data to those given in Table 2 for construction were used in these calculations. The energy consumption taken into account includes materials production and installation. This part of the life cycle is given in Figure 10 vs. time for NPL.

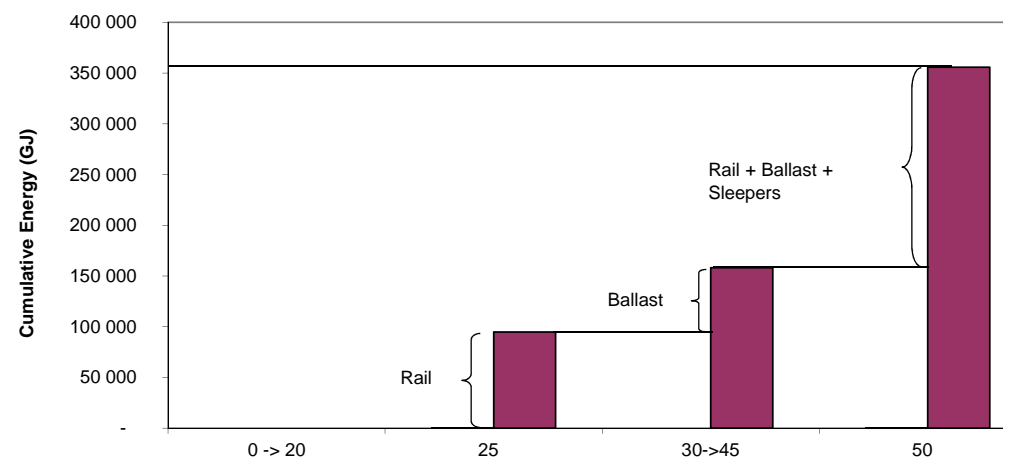

Figure 10: Cumulative maintenance energy for NML.

\subsection{Operations phase results}

Conventional parameters were used to run the train model. The mass $\mathrm{M}$, coefficient of rotating masses $\mathrm{k}$, coefficients A, B, C and $\eta$ were extracted from Jeunesse and Rollin (2004), Andersson and Lukaszewicz (2006), Fayet (2008) and Rochard and Schmid (2000). They have already been validated as a comprehensive parameter set (Bosquet et al., 2013). For electricity production, French data were used. The simulations were performed for a 50-year use period, as defined by the FU.

Results are shown in Figure 11. The consumption model can clearly differentiate the two scenarios. As observed, NML is more expensive from an energy point of view, i.e. with a $35 \%$ higher price than NPL. This difference is 
mainly due to the fact that NPL is shorter than NML. Furthermore, for freight traffic, the conventional line is more price competitive than the mixed line with respect to energy. The NPL therefore is more attractive for freight traffic from a strict energy point of view.

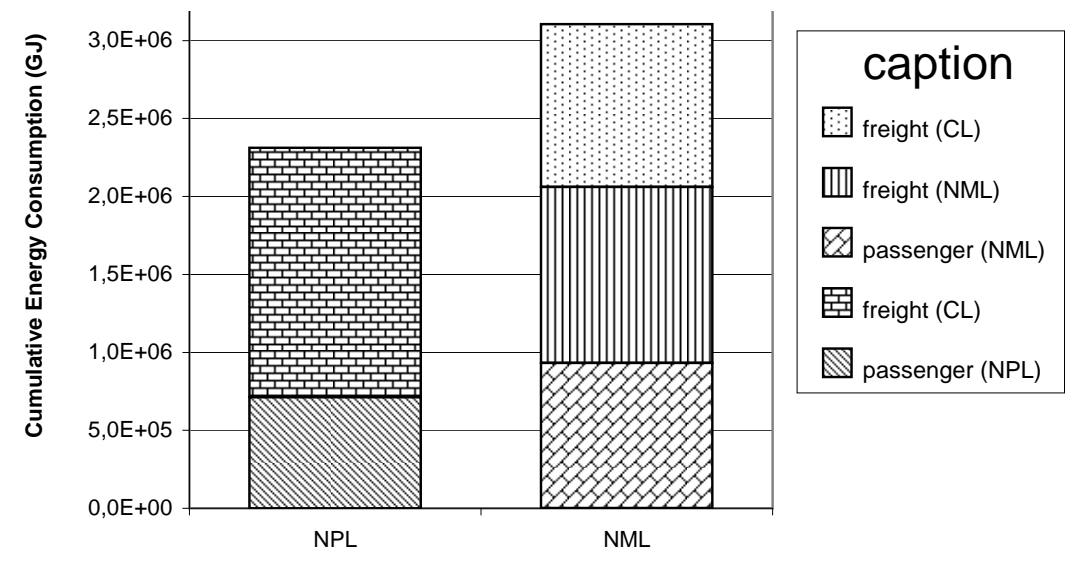

Figure 11: A comparison of energy consumed during the 10-year operations phase - efu 7.

\subsection{Total life cycle results (efu 1 to efu 7)}

The total primary energy results (operations, construction and maintenance) were calculated and have been displayed in Figure 12. Let's note from the graph that NML consumes more energy, i.e. $30 \%$ after 50 years in comparison with NPL. This graph also compares the energy spent on infrastructure construction and (if applicable) maintenance with the primary energy spent during operations. After a 50-year service life, infrastructure construction and maintenance in the Montpellier-Perpignan case study account for $16 \%$ of the total energy cost for NML and $20 \%$ for NPL.

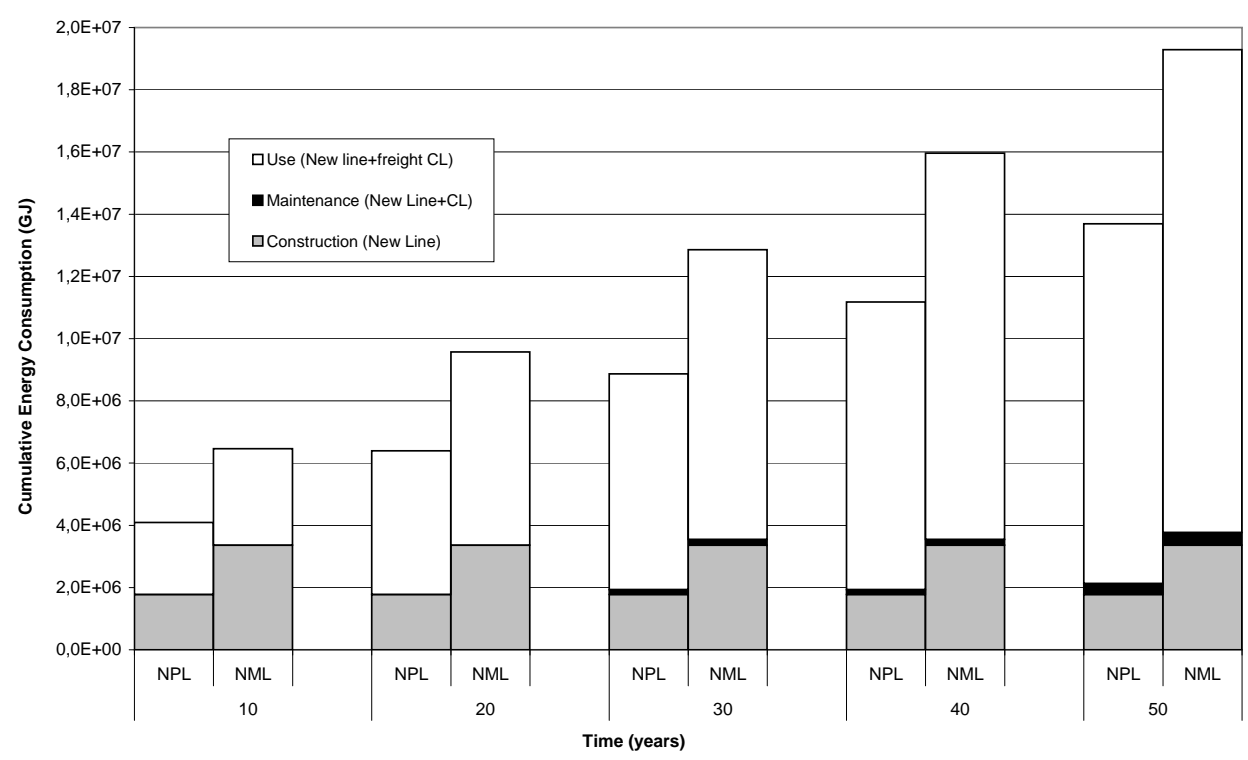

Figure 12: Cumulative energy spent during the operations and construction phases. 


\section{Discussion}

\subsection{New results at the pre-project stage with PEAM}

The purpose of this paper has been to assess, at the pre-project stage, a new HSL project linking two points in a given territory and ensuring a given train traffic level over a 50-year service life. A conventional line (freight and regional trains) already exists within the study area, thus generating variants that include both a new line and a mixed line. A number of methodological considerations for the LCA of HSL projects have already been proposed (Vandanjon et al., 2012). The results obtained here provide the per-km primary energy consumption ratios for efu 3 through efu 6, which will prove useful for any subsequent project assessment. Moreover, the other territory-dependent efu ( 1 and 2 ) have been carefully examined in the present paper using available data, such as earth movement volumes and longitudinal profiles.

The PEAM method has been developed in collaboration with French railway owner RFF and applied at several steps of the HSL life cycle; it appears to offer a powerful tool for assessing projects during the preliminary stage, when defining variants within a given territory.

One major contribution of this study is to clarify the issues presented in public debate. In France, for this type of project, a public hearing is required. Such a hearing was held for the Montpellier-Perpignan HSL (recorded hearing minutes are available at http://cpdp.debatpublic.fr/cpdplnmp/). During the debates, some non-specialists expressed the opinion that a mixed line is better for the environment than an exclusively passenger line because it offers more opportunities for the modal shift of freight from road to rail. This perspective however did not take into account the additional energy cost associated with a mixed line. Another important contribution of our work has been to clarify debate arguments by providing an energy assessment methodology.

\subsection{Applicability of PEAM to other projects}

The PEAM method may be applied to projects of various sizes, i.e. lengths of between $10 \mathrm{~km}$ and $1,000 \mathrm{~km}$. Since we are encouraging application of this methodology to other projects, let's caution that the figures found in our study cannot be directly extrapolated to another country. For example, the ratios obtained between the efu integrate the indirect impacts of energy sources that are typical of France (3.08).

\subsection{Hypotheses and limits of PEAM}

Moreover, even though many indicators can be calculated according to LCA, the present method has only been applied to studying energy consumption as one of the major parameters in any global assessment, which also introduces sustainability considerations. In the context of increasing energy prices per MJ sold on the market due to future depletion concerns, energy remains a very understandable parameter that can easily be considered on its own for discussion purposes and decision-making among stakeholders and users. Moreover, it can be easily measured and modeled by researchers under various methodological assumptions, including train consumption modeling on an itinerary and LCA applied to technical construction strategies.

The life cycle of vehicles has not been included in the present study since it remains constant in both scenarios.

In our method, only the service life has been investigated and the end of life has not been integrated. For the time being, only energy has been presented, and it was shown that our method yields different results between the two variants. For a fuller understanding of these scenarios, it would be beneficial to calculate other impacts classically found in LCA and then to verify the extent to which energy results and variant rankings remain similar for other indicators.

In examining these variants, road rehabilitation also induces mobility changes that are not addressed at this stage but could be integrated in order to conduct a more sustainable approach.

The time required to connect two points within a given territory differs for each variant. From a mobility point of view, travel time should be taken into account. Although not yet integrated into our functional unit, future works should incorporate the notion of travel time.

As a final consideration, these results, as would be expected, are highly dependent on the hypotheses and questions posed. For all these reasons, it would be useful to continue developing this method in conjunction with other indicators so as to check for other important impacts to include in an eco-design approach. 


\section{Conclusion}

The construction of a new railway line may be necessary for several reasons, among which increasing capacity, reducing travel time and allowing for other train gauges. The new infrastructure not only will have an impact on other modes of transport (road and air) but will also change the distribution of train traffic. The challenge for this paper has consisted of collating the results from previous models developed separately into an integrated approach for a new HSL project, with the ultimate aim of performing an eco-design at the project level in using energy consumption as a valuable criterion for resource conservation. To achieve this goal, numerical models were developed to simulate energy consumption during both operations and construction/maintenance. An efficient methodology called PEAM was proposed for comparing variants at the pre-project stage, as regards energy consumption. Construction, maintenance and operations phases can thus now be investigated comprehensively, and their respective influences determined using quantified energy results.

\section{Acknowledgements}

The study was conducted with the support of Réseau Ferré de France (RFF), owner of the national railway network, as part of a partnership with Ifsttar. The authors would also like to thank Inexia (contract manager) for providing data relative to a viaduct. Special gratitude is also addressed to: Olivier Cazier, Edouard Parant, Nicolas Aladern from RFF, and Amandine Fargier and Christophe Ropert from Ifsttar.

\section{References}

AFNOR, fev 2006. Environmental quality of construction products - Energy and transport data sheet, standard FD P 01-015.

Akerman, J., 2011. The role of high-speed rail in mitigating climate change - the swedish case europabanan from a life cycle perspective. Transportation Research Part D: Transport and Environment 16 (3), 208 - 217.

Andersson, E., Lukaszewicz, P., 2006. Energy consumption and related air pollution for Scandinavian electric passenger trains. Tech. rep., Department of Aeronautical and Vehicle Engineering Royal Institute of Technology.

Bosquet, R., Vandanjon, P.-O., Coiret, A., Lorino, T., 2013. Model of high-speed train energy consumption. In: World Academy of Science, Engineering and Technology. Vol. 78.

Botniabanan-AB, march 2010. Environmental product declaration for freight transport on the Bothnia Line. Tech. rep., EPD - Freight Transport, reg. no. S-P-00195 UN CPC 6512.

Boullanger, B., 2008. Modeling and simulation of future railways. Ph.D. thesis, Royal Institute of Technology KTH Elektro-och.

Capony, A., Muresan, B., Dauvergne, M., Auriol, J. C., Ferber, V., Jullien, A., Jan. 2013. Monitoring and environmental modeling of earthwork impacts: A road construction case study. Resources, Conservation and Recycling 74, pp.124-133.

URL http://hal .archives-ouvertes.fr/hal-00851528

Chang, B., Kendall, A., 2011. Life cycle greenhouse gas assessment of infrastructure construction for california's high-speed rail system. Transportation Research Part D: Transport and Environment 16 (6), 429 - 434.

URL http://www.sciencedirect.com/science/article/pii/S1361920911000484

Chester, M. V., Horvath, A., 2009. Environmental assessment of passenger transportation should include infrastructure and supply chains. Environmental Research Letters 4, 024008.

Chester, M. V., Horvath, A., 2010. Life-cycle assessment of high-speed rail: the case of California. Environmental Research Letters 5 (1), 1-8.

Ecoinvent, march 2011. Ecoinvent database. CML 2001

URL http: //db.ecoinvent.org/ecoquery/processdetail.php

Fayet, P., 2008. Modélisation des réseaux électriques ferroviaires alimentés en courant alternatif. Ph.D. thesis, EEA Lyon.

Federici, M., Ulgiati, S., Basosi, R., 2009. Air versus terrestrial transport modalities: An energy and environmental comparison. Energy 34 (10), $1493-1503$.

Garcia, A., december 2010. High speed, energy consumption and emissions. Tech. rep., UIC.

Hoffrichter, A., Silmon, J., Iwnicki, S., Hillmansen, S., Roberts, C., 2012. Rail freight in 2035 - traction energy analysis for high-performance freight trains. Proceedings of the Institution of Mechanical Engineers, Part F: Journal of Rail and Rapid Transit 226 (6), 568-574. URL http://pif . sagepub.com/content/226/6/568. abstract

Ifsttar, RST MEDDE, 2014. Ecorce 2 - ecocomparateur route construction entretien v2. URL Ecorce2. ifsttar.fr

International Energy Agency, 2013. Online; accessed 22-January-2013.

URL http://http: //www. iea.org>Home>Statistics>World->Statisticsfor2009->Balances

Janic, 2003. High-speed rail and air passenger transport: a comparison of the operational environmental performance. Proceedings of the Institution of Mechanical Engineers, Part F: Journal of Rail and Rapid Transit 217.

Jeunesse, A., Rollin, M., mars 2004. La motorisation du TGV POS. Revue Générale des Chemins de fer.

Jullien, A., Dauvergne, M., november 2012. RN7, exploitation des données de chantier pour effectuer L'ICV et les calculs ECORCE. Indicateurs environnementaux, sociaux et économiques, pour l'évaluation de chantiers de terrassement. 
Lee, C., Lee, J., Kim, Y., 2008. Comparison of environmental loads with rail track systems using simplified life cycle assessment (LCA). In: Transport, U. (Ed.), WIT Transactions on The Built Environment. Vol. 101. pp. 1-6.

Lee, T., Park, C., Choi, S., Kim, K., may 2011. A study of the train performance simulation for korean next generation high-speed train. WCRR. Leheis, S., 2012. High-speed train planning in France: Lessons from the Mediterranean TGV-line. Transport Policy 21 (0), 37 - 44.

Lindgreen, E., Sorenson, S. C., february 2005. Simulation of energy sinsumption and emissions from rail traffic. Tech. rep., Technical University of Denmark, Department of Mechanical Engineering.

Lukaszewicz, P., january 2007. Running resistance - results and analysis of full-scale tests with passenger and freight trains in sweden. Proceedings of the Institution of Mechanical Engineers, Part F: Journal of Rail and Rapid Transit 221, $183-192$.

Raghunathan, R. S., Kim, H.-D., Setoguchi, T., 2002. Aerodynamics of high-speed railway train. Progress in Aerospace Sciences 38 (6-7), 469 514.

RFF, 2009. The european high speed network, $250 \mathrm{~km} / \mathrm{h}$ and above. [Online; accessed mars-2012].

URL www.rff.fr/en->the-network->maps->Europeanmaps

RFF, SNCF, février 2006. In 3278 - Référentiel technique pour la réalisation des LGV - partie génie civil - tome 1 - LGV « Voyageurs » caractéristiques générales, référentiel Infrastructure - Document d'application.

Rochard, B., Schmid, F., 2000. A review of methods to measure and calculate train resistances. Proceedings of the Institution of Mechanical Engineers, Part F: Journal of Rail and Rapid Transit 214 (4), 185-199.

Rozycki, C., Koeser, H., Schwarz, H., 2003. Ecology profile of the german high-speed rail passenger transport system, ice. The International Journal of Life Cycle Assessment 8 (2), 83-91.

URL http://dx.doi.org/10.1007/BF02978431

SETRA, december 2000. ICTAAL - instruction sur les conditions techniques d'amÉnagement des autoroutes de liaison.

UIC, H. S. D., July 2013. High speed lines in the World, 1-13.

van Wee, B., van den Brink, R., Nijland, H., 2003. Environmental impacts of high-speed rail links in cost-benefit analyses: a case study of the dutch zuider zee line. Transportation Research Part D: Transport and Environment 8 (4), 299 - 314.

Vandanjon, P.-O., Coiret, A., Muresan-Paslaru, B., Fargier, A., Bosquet, R., Dauvergne, M., Jullien, A., François, D., Labarthe, F., July 2012. Practical guidelines for Life Cycle Assessment applied to railways project. In: Proc. International Symposium on Life Cycle Assessment and Construction, Nantes, France. 